\title{
Hyperinsulinemic clamp modulates milk fat globule lipid composition in goats
}

\author{
N. Argov-Argaman, ${ }^{* 1}$ T. Mbogori, ${ }^{*}$ C. Sabastian, ${ }^{*}$ A. Shamay, $\dagger$ and S. J. Mabjeesh ${ }^{\star}$ \\ *Department of Animal Sciences, The Robert H. Smith Faculty of Agriculture, The Hebrew University of Jerusalem, POB 12, Jerusalem, Israel \\ †Animal Science Department, The Volcani Center, The Ministry of Agriculture, POB 6, Bet Dagan, Israel
}

\begin{abstract}
We determined the effect of insulin on milk fatty acid (FA) and lipid composition in goats. Four dairy goats, $150 \mathrm{~d}$ in milk, were subjected to hyperinsulinemic clamp (treatment) or saline (control) infusion for $4 \mathrm{~d}$ in a crossover design study. Composition and concentration of plasma and milk FA, triglycerides, phospholipids, sphingolipids, and cholesterol were determined. Mammary gland biopsies were taken at the end of each experimental period and lipogenic gene expression was determined. Plasma insulin was elevated 3.5-fold, whereas plasma glucose remained constant during the treatment period. Feed intake decreased by $26 \%$ and fat yield decreased by $17 \%$ relative to controls. No change in nonesterified FA concentration was found between controls and treatment. Compared with controls, insulin decreased yield of long-chain saturated FA by $14 \%$. Milk concentration of long-chain FA was reduced by $3 \%$, whereas that of medium-chain $\mathrm{FA}$ increased by $5 \%$ during the treatment compared with controls. Hyperinsulinemic clamps increased the yields of milk phospholipids by $9 \%$ and cholesterol by $16 \%$, whereas it only tended to decrease triglyceride yields (by 11\%). Hyperinsulinemic treatment resulted in compositional changes in the milk fat globule membrane, as reflected by 15 and $9 \%$ decreases in phosphatidylethanolamine and phosphatidylcholine concentrations, respectively. Lipogenic gene expression of acyl coenzyme A carboxylase, stearoyl coenzyme A desaturase, and FA synthase did not change, whereas lipoprotein lipase gene expression tended toward an increase in the treatment period compared with controls. Hyperinsulinemic clamps reduce the availability of long-chain FA, which are considered to originate from the diet and adipose lipolysis for milk lipid synthesis by the mammary gland of goats. Under these conditions, long-chain FA might be preferentially channeled to phospholipid rather than triglyceride synthesis, hence increasing phospholipid yields. Mechanisms determining FA distribution among
\end{abstract}

Received March 25, 2012.

Accepted June 25, 2012.

${ }^{1}$ Corresponding author: argov@agri.huji.ac.il milk lipid components and the consequences of altered milk fat globule membrane lipid composition remained to be elucidated.

Key words: insulin, milk fat, milk fat globule membrane

\section{INTRODUCTION}

Fatty acids in milk are mainly esterified to a glycerol or sphingosine backbone, to form triglyceride and phosphoglycerides, or sphingolipids, respectively (Jensen and Thompson, 1995). Milk fat consists of 96 to $97 \%$ triglycerides and 0.5 to $1 \%$ structural lipids, mainly phosphoglycerides and sphingolipids (i.e., phospholipids; Bitman and Wood, 1990). The amount and composition of milk fat depend on several factors, including animal characteristics such as breed and lactation stage, and feed characteristics such as energy intake (Jensen, 2002). However, the factors inducing changes in milk lipid species have been little studied.

The variety of lipid species in milk is attributed to the unique secretion pathway of milk fat. As part of this pathway, the mammary gland epithelial cell membrane envelops the emerging triglyceride droplet, thereby forming the milk fat globule membrane (Mather and Keenan, 1998). This membrane consists of complex structural lipids, including phospholipids, glycolipids, and cholesterol, as well as proteins, all derived from the apical membrane of the secreting epithelial cells. Therefore, the milk fat globule membrane is commonly used to characterize mammary gland epithelial cell membrane proteome and lipidome (Argov-Argaman et al., 2010).

Accumulating evidence indicates that cell-membrane composition plays an active role in cell metabolism, secretion, and sensitivity to external signals, such as hormones. This association was shown for muscle cells and sensitivity to insulin (Storlien et al., 1996), mammary gland epithelial cells in relation to their differentiation status (Glunde et al., 2004), and for Escherichia coli and their secretion capacity (Mikhaleva et al., 2001; Golovastov et al., 2002). In the mammary gland, the possible association between the membrane composition of epithelial cells and their lipogenic capacity was 
described in a single paper (Lopez et al., 2008). Another factor that is known to induce changes in fat concentration and yields in ruminants is insulin. However, its role in regulating milk fat globule membrane composition has never been studied.

Plasma insulin concentration and the animal energy balance are major factors influencing milk fat concentration and composition (Griinari et al., 1997; de Vries and Veerkamp, 2000). The effect of insulin on milk fat has been studied in dairy cows and goats (Corl et al., 2006; Li et al., 2007). Nevertheless, the mechanisms underlying the changes in milk fat associated with plasma insulin concentration are still under debate. It is not clear if the mammary gland is responding to the variations in insulin concentration or to the preferential channeling of precursors and metabolites to adipose and muscle tissues under high plasma insulin concentrations (Jenny et al., 1974; Brockman and Laarveld, 1986; Sutton et al., 1988).

The effects of nutrition and metabolic hormones on lipogenic capacity of the mammary gland, as well as of the pathways for obtaining milk fat precursors, are not well understood in goats. Moreover, measurements have been confined to studies examining the effects of plant oils and grass hay-based diets (Bernard et al., 2005; Ollier et al., 2009). Also, interspecies differences in the reactions induced by metabolic pathways and nutrition have been documented (Ahnadi et al., 2002; Chilliard et al., 2003; Bernard et al., 2008).

Here, milk fat yield and composition, and the expression levels of genes in the mammary gland regulating de novo synthesis and lipid uptake from the plasma were studied in Saanen goats under high plasma insulin concentrations induced by a chronic euglycemic-hyperinsulinemic clamp. The milk fat globule membrane composition was also studied in relation to the elevated plasma insulin concentration. The aim of the present study was 2-fold: (1) to determine whether modulation of mammary gland lipogenic capacity also induces changes in phospholipid membrane composition, and (2) to acquire data on the response of goats to hyperinsulinemic clamps, toward a further understanding of interspecies differences.

\section{MATERIALS AND METHODS}

\section{Goats}

All procedures involving the 4 Saanen goats used in this study were approved by the Hebrew University Institutional Animal Care and Use Committee (Jerusalem, Israel). At the start of the study, the goat BW averaged $51 \pm 7.5 \mathrm{~kg}$ and they were $100 \pm 15 \mathrm{~d}$ postpartum. They were fed ad libitum ( $\pm 10 \%$ refusals of the daily meal) a ration composed of (70:30, on DM basis) a commercial pelleted dairy concentrate (mix \#16400; Ambar Feed Mill, Granot, Israel) and a roughage TMR (Newmix; International Feeding Center, Massuot Itzhak, Israel). The pellets included (DM basis) $22.9 \% \mathrm{CP}(\mathrm{N} \times 6.25)$, $20.4 \%$ NDF, $6.3 \%$ ADF, 1.79 Mcal of ME (calculated)/ $\mathrm{kg}$ of DM, and a mix of vitamins and minerals (Ambar Ltd., Hadera, Israel). The TMR was composed (on DM basis) of wheat silage $(33.3 \%)$, wheat straw (23.3\%), wheat bran (4\%), ground wheat grains $(4 \%)$, wet corn gluten feed $(10.0 \%)$, distillers dried grains with solubles (4.8\%), molassed soybean hull (19.2\%), and a vitamin and mineral premix (0.7\%; Ambar Feed Mill). The DM ratio of the TMR was $58.6 \%$ and it had $10.4 \% \mathrm{CP}$, $51 \% \mathrm{NDF}, 28 \% \mathrm{ADF}$, and $1.39 \mathrm{Mcal}$ of $\mathrm{ME} / \mathrm{kg}$ of DM. Throughout the experiment and between infusion periods, the ration was delivered by automatic feeders (12 equal meals at 2 -h intervals).

\section{Experimental Design}

Goats were assigned to hyperinsulinemic clamp treatment according to a balanced crossover design (2 $\times 2$ ). The experiment consisted of 2 periods (separated by 2 wk) of continuous intravenous infusions of either saline $(240 \mathrm{~g} / \mathrm{d}, \mathrm{pH} 7.4)$ or insulin. One week before the start of each infusion period, goats were placed in metabolic crates for acclimatization. Between infusion periods, animals were kept on floor pens and fed by automatic feeders.

For the first $4 \mathrm{~d}$ of each period, venous blood was sampled by venipuncture into heparinized tubes daily at 0800 and $2000 \mathrm{~h}$. One portion of these samples was analyzed for plasma glucose with a handheld glucose meter (Accu-Chek Sensor Comfort; Roche Ltd., Basel, Switzerland) to provide target glycemia levels for each goat during the insulin clamping. The rest of the samples were centrifuged at $2,000 \times g$ for $15 \mathrm{~min}$ at $4^{\circ} \mathrm{C}$ to collect plasma, which was stored at $-20^{\circ} \mathrm{C}$ for further analysis.

The insulin solutions for infusion were prepared daily for each goat from frozen aliquots $(1 \mathrm{mg}$ of insulin $/ \mathrm{mL}$ of sterile water containing $1 \%$ (wt/vol) BSA and 50 $\mu \mathrm{L}$ of $6 \mathrm{~N} \mathrm{HCl}$ to dissolve the insulin) of bovine insulin (I-5500, Sigma-Aldrich Co., St. Louis, MO). Aliquots $(2.88 \mathrm{~mL})$ were slowly thawed and brought to $240 \mathrm{~mL}$ with sterile saline containing $0.1 \%$ BSA. The insulin solution was infused $(10 \mathrm{~mL} / \mathrm{h})$ i.v. through a sterile filter $(0.45 \mu \mathrm{m})$ to deliver $120 \mu \mathrm{g}$ of insulin/h. During the insulin clamping, euglycemia was maintained by infusion of a glucose solution [50\% (wt/vol) glucose monohydrate solution; Teva Medical Ltd., Netanya, Israel] at various rates. Within $15 \mathrm{~min}$, blood glucose was determined with the handheld glucose meter, and 
the glucose infusion rate was adjusted as needed. At the outset, blood sampling was frequent (20 to $30 \mathrm{~min}$ ) until euglycemia and glucose infusion rates became more stable; subsequently, blood samples were taken every 4 to $6 \mathrm{~h}$. Milking was performed at 0700 and 1900 $\mathrm{h}$, and milk yield was recorded at each milking. One subsample was taken from the morning and following evening's milking and composited (1:1) into containers that included bronopol (2-bromo-2-nitropropane-1,3diol and 2-bromo-2-nitropropanol) for analysis of fat, protein, and lactose with an infrared milk analyzer (Central Milk Laboratory, Caesarea, Israel). A second subsample of milk was frozen at $-20^{\circ} \mathrm{C}$ for analysis by GC and HPLC for milk FA and phospholipid composition.

On the last day of the experiment, mammary tissue biopsies were taken under general anesthesia. After proper preparation of the skin area on the upper part of the gland, an incision of $2 \mathrm{~cm}$ was made in the skin and subdermis. The fascia, fat tissue, and connective tissue were removed by sharp dissection until the mammary tissue gland was visible. Approximately $2 \mathrm{~g}$ of tissue was taken, rinsed in $0.9 \%$ saline sterile solution, inspected to verify tissue homogeneity, and divided into 2 equal portions: one was snap-frozen in liquid nitrogen and the other was placed in RNAlater solution (Applied Biosystems Inc., Ambion, Foster City, CA). Frozen samples were then stored at $-80^{\circ} \mathrm{C}$ and the others were stored at $4^{\circ} \mathrm{C}$.

\section{Lipid Extraction and Analysis}

Chemicals and Reagents. For lipid extraction, analytical reagent-grade methanol and chloroform were purchased from Bio-Lab Ltd. (Jerusalem, Israel). For HPLC analysis, dichloromethane, methanol and ethanol (HPLC grade and analytical reagent grade) were purchased from Bio-Lab Ltd. The triglyceride standard, triolein ( $>99 \%$ pure), was purchased from Supelco Inc. (Bellefonte, PA). Cholesterol (>99\% pure) and phospholipid standards were supplied by SigmaAldrich Israel Ltd. (Rehovot, Israel), and consisted of 1,2-dioleoyl-sn-glycero-3-phosphoethanolamine (PE; purity 99\%), phosphatidyl inositol (PI; L- $\alpha$ phosphatidylinositol ammonium salt, from bovine liver, purity 98\%), phosphatidylserine (PS; 1,2-dioleoyl-sn-glycerol3-phospho-L-serine sodium salt, purity 95\%), phosphatidylcholine (PC; 1,2-dioleoyl-sn-glycero-3-phosphocholine, purity 99\%), and sphingomyelin (from bovine brain, purity 97\%). As an internal standard for FFA, C11:0 (undecanoic acid, purity 99\%; Sigma-Aldrich Israel Ltd.) was used. For preparation of methyl esters, methanol (analytical reagent grade) was purchased from
Bio-Lab Ltd., sulfuric acid from Bet Dekel (Ra'anana, Israel) and petroleum ether (analytical reagent grade) from Gadot Lab Supplies Ltd. (Netanya, Israel). For GC analysis, retention times were determined by injection of commercial mixes of FA methyl ester (FAME) standards from C14:0 to C22:6n-3 (PUFA-2 Animal Source), FAME mix of C8:0 to C24:0 (PUFA-3), and FAME mix C4:0 to C24:0 (PUFA-4), all purchased from Supelco Inc.

Extraction of Total Lipids from Milk. An adapted protocol of the cold extraction procedure developed by Folch et al. (1957) was used for the extraction of total lipids from the milk. For the GC samples, $30 \mu \mathrm{L}$ of internal standard C11:0 was added to the samples before extraction. Total lipids (both GC and HPLC samples) were extracted from $0.5 \mathrm{~mL}$ of milk with 10 $\mathrm{mL}$ of chloroform-methanol $(2: 1, \mathrm{vol} / \mathrm{vol})$ as previously described (Mesilati-Stahy et al., 2011). For the HPLC analysis, $100 \mu \mathrm{L}$ of chloroform-ethanol (97:3 vol/vol) was added to the evaporated tubes containing lipids and stored at $-20^{\circ} \mathrm{C}$ until injection into the HPLC. For the GC analysis, FAME were generated.

Extraction of Total Lipids from Plasma. Plasma samples from the last day of the experiment were used for the GC analysis and $\mathrm{d} 3$ samples were used for the HPLC analysis. Plasma samples were taken on the last $2 \mathrm{~d}$ of the experiment under the assumption that the effect of plasma insulin peaks after the second day of infusion. Total lipids were extracted from the plasma using the protocol described above for milk samples and methyl esters were generated as described below.

FAME Preparation. Fatty acid methyl esters were prepared with 95:5 (vol/vol) methanolic $\mathrm{H}_{2} \mathrm{SO}_{4}$ and dissolved in petroleum ether using the following protocol: $2.5 \mathrm{~mL}$ of methanolic $\mathrm{H}_{2} \mathrm{SO}_{4}$ was added to the tubes containing lipids, caps were closed, and the tubes were placed in a water bath at $65^{\circ} \mathrm{C}$ for $1 \mathrm{~h}$. Then, the tubes were cooled to room temperature and 1.9 $\mathrm{mL}$ of PE was added. This mixture was vortexed until homogeneous and $3.5 \mathrm{~mL}$ of double-distilled water was added. The upper layer was collected and evaporated in a vacuum oven to remove the solvent. 1,2-Dioleoyl-snglycero-3-phosphoethanolamine $(100 \mu \mathrm{L})$ was added to the tubes to dissolve the methyl esters. Then samples were stored at $-20^{\circ} \mathrm{C}$ until injection for GC analysis.

GC Analysis of FA Composition. Chromatographic analysis was performed with a gas chromatograph (Agilent Technologies Inc., Wilmington DE) equipped with a fused-silica $(60 \mathrm{~m} \times 0.25 \mathrm{~mm}$ i.d., $0.25-\mu \mathrm{m}$ film) capillary column (DB-23, Agilent Technologies Inc.), under the following oven temperature program conditions: heating from 130 to $170^{\circ} \mathrm{C}$ at a rate of $27^{\circ} \mathrm{C} / \mathrm{min}$, from 170 to $215^{\circ} \mathrm{C}$ at $2^{\circ} \mathrm{C} / \mathrm{min}$, holding at 
Table 1. Fatty acids grouped by source and biochemical characteristics ${ }^{1}$

\begin{tabular}{ll}
\hline Group & FA $^{2}$ \\
\hline C8:0-C15:0; saturated & C8:0, C10:0, C12:0, C12:0 BC(a), C12:0 BC(b), C13:0, C14:0, C15:0 \\
C8:0-C15:1; total & C8:0, C10:0, C10:1, C12:0, C12:0 BC(a), C12:0 BC (b), C13:0, C14:0, C14:1, C14:1 BC(a), C14:1 BC (b), \\
& C15:0, C15:1 \\
C17:0-C24:0; saturated & C17:0, C18:0, C20:0, C22:0, C23:0, C24:0 \\
C17:0-C24:0; total & C17:0, C17:1, C18:0, trans C18:1n-9, cis C18:1n-9, C18:1n-7, trans-9, trans-12 C18:2n-6, cis-9, cis-12 C18:2n-6, \\
& trans-10, cis-12 C18:2n-6, trans-9, trans-11 C18:2, cis-11, cis-13 C20:2, C20:3n-6, C20:3n-3, C20:4n-6, C22:0, \\
& C20:5n-3, cis-13C22:1, C23:0, C22:4n-6, C24:0, C22:6n-3 \\
Saturated total & trans-9, trans-12 C18:2n-6, cis-9, cis-12 C18:2n-6, C18:3n-6, cis-9, cis-12, cis-15 C18:3n-3, cis-9, trans-11 C18:2n-6, \\
PUFA & trans-10, cis-12 C18:2, trans-10, cis-12 C18:2n-6, trans-9, trans-11 C18:2, cis-11, cis-13 C20:2, C20:3n-6, C20:3n-3, \\
& C20:4n-6, C22:0, C20:5n-3, C22:4n-6, C22:6n-3 \\
& C 10:1, C14:1, C14:1 BC(a), C14:1 BC(b), C15:1, C16:1 (a), C16:1 (b), cis-9 C16:1n-7, C 16:1 BC(a) \\
MUFA & C16:1 BC(b), C17:1, trans C18:1n-9, cis C18:1n-9, C18:1n-7, cis-13 C22:1, C20:1n-9 \\
& C18:3n-3, C20:3n-3, C20:5n-3, C22:6n-3 \\
n-3 & trans-9, trans-12 C18:2n-6, cis-9, cis-12 C18:2n-6, C18:3n-6, cis-9, trans-11 C18:2n-6, C20:3n-6, C20:4n-6, \\
n-6 & C22:4n-6 \\
\end{tabular}

${ }^{1}$ Fatty acids were classified into different classes according to their chemical characteristics and perceived origin.

${ }^{2} \mathrm{BC}=$ branched-chain FA.

$215^{\circ} \mathrm{C}$ for $8 \mathrm{~min}$, heating from 215 to $250^{\circ} \mathrm{C}$ at $40^{\circ} \mathrm{C} /$ min, and holding at $250^{\circ} \mathrm{C}$ for $5 \mathrm{~min}$. The run time was 37.9 min. Helium was used as a carrier gas at $2.21 \mathrm{~mL} /$ min. The temperature of the flame ionization detector was $270^{\circ} \mathrm{C}$ and that of the injector was $280^{\circ} \mathrm{C}$. Air and hydrogen flows were adjusted to give a maximal detector response. A split ratio of 100:1 was used and $1 \mu \mathrm{L}$ of sample was injected. Peak identification was based on relative retention times of 3 external standards and on GC-MS results under the same conditions from analysis by the Interdepartmental Analytical Unit, The Robert H. Smith Faculty of Agriculture, Food and Environment (Hebrew University). After FA were identified and analyzed, they were grouped into 9 classes according to their length and thus alleged origin, and according to their chemical properties - number of double bonds and the position of the first double bond from the methyl end of the carbon chain (Table1).

HPLC Analysis of Polar and Neutral Lipids. Quantification of phospholipids and determination of polar lipid classes were performed by HPLC (HP 1200; Agilent Technologies Inc.) combined with an evaporative light-scattering detector (ELSD1200; Agilent Technologies Inc.). The separation process was managed by ChemStation software (Agilent Technologies Inc.), which permitted the acquisition of data from the ELSD1200 detector, with an injection volume of $10 \mu \mathrm{L}$. Calibration and lipid concentration and composition were determined using external standards (Sigma-Aldrich Israel Ltd.). The separation protocol was conducted as previously described by Yandrasitz et al. (1981) using normal-phase chromatography on a silica column (Zorbax; Agilent Technologies Inc.).

\section{RNA Extraction and Analysis}

Total RNA was isolated from mammary gland tissues by the acid guanidinium thiocyanate phenol-chloroform extraction method (Chomczynski and Sacchi, 1987). Briefly, tissues were harvested in TRI Reagent (Molecular Research Center Inc., Cincinnati, $\mathrm{OH}$ ) according to the manufacturer's protocol. The amount and quality of RNA were determined by NanoDrop spectrophotometry (NanoDrop Technologies Inc., Wilmington, DE). The RNA was kept at $-80^{\circ} \mathrm{C}$ until further analysis.

Reverse Transcription. The RNA samples were treated with DNase solution (Ambion Inc., Austin, TX) following the manufacturer's instructions. Then RNA was reverse-transcribed according to the ABgene UK (Cambridge, UK) instructions in a final volume of 20 $\mu \mathrm{L}$. First, $1 \mu \mathrm{g}$ of RNA with anchored oligo-dT primers $(500 \mathrm{ng})$ and random hexamer $(1,200 \mathrm{ng})$ at a ratio of 1:3 (total volume of $12 \mu \mathrm{L}$ ) was heated at $70^{\circ} \mathrm{C}$ for 5 min. Then, $4 \mu \mathrm{L}$ of cDNA synthesis buffer $(5 \times), 1 \mu \mathrm{L}$ of Verso enzyme, $2 \mu \mathrm{L}$ of deoxyribonucleotide triphosphate $(\mathrm{dNTP}) \mathrm{mix}$, and $1 \mu \mathrm{L}$ of reverse transcription enhancer were added to a final volume of $20 \mu \mathrm{L}$. The reaction was run for $1 \mathrm{~h}$ at $47^{\circ} \mathrm{C}$ and the enzyme was stopped by heating to $95^{\circ} \mathrm{C}$ for 2 min. The product (cDNA) was kept at $-20^{\circ} \mathrm{C}$.

Real-Time PCR. The RNA samples were reversetranscribed as described. The gene expression levels of stearoyl-CoA desaturase (SCD), FA synthase (FAS), acyl-CoA carboxylase (ACC), lipoprotein lipase (LPL), and diacylglycerol acyl transferase (DGAT) were analyzed by real-time PCR (RT-PCR) with the StepOnePlus Real-Time PCR System (Applied Biosys- 
tems Inc.). The $16 \mathrm{~S}$ mRNA expression level was used to normalize the results. Reaction was carried out in a final volume of $10 \mu \mathrm{L}$ : $5 \mu \mathrm{L}$ of SYBR Green mix (ABgene UK), $0.5 \mu \mathrm{L}$ of $5 \mu M$ forward primer, $0.5 \mu \mathrm{L}$ of 5 $\mu M$ reverse primer, and $4 \mu \mathrm{L}$ of template $(0.5$ to $10 \mathrm{ng}$ of $\mathrm{cDNA} / \mu \mathrm{L})$. After enzyme activation at $95^{\circ} \mathrm{C}$ for 15 min, 40 cycles were run of 1 -min denaturation at $95^{\circ} \mathrm{C}$, 2-min annealing at $60^{\circ} \mathrm{C}$, and 1 -min extension at $72^{\circ} \mathrm{C}$. The amplified PCR product was analyzed with the StepOne Real-Time PCR System. At the end of the RTPCR run, a melting curve was determined to verify the presence of a single amplicon. For each gene, a standard curve was generated to determine reaction efficacy. The primers used were as follows $\left(5^{\prime} \rightarrow 3^{\prime}\right.$, where $\mathrm{F}=$ forward and $\mathrm{R}=$ reverse): SCD (F), TGTCCACCATGAACCACGTGT and SCD (R), CCACCCCTTAGCTGATGCATT; FAS (F), GGCAGATGATGCGGGAGAA and FAS (R) GCGACACGACAGTGAAGGCT; ACC (F), CGGGGAGATCCTGAACAACT and ACC (R), CTGCCATGAACGATGACAACC; LPL (F), TACCCTAACGGAGGCACTTTCC and LPL (R), TGCAATCACACGGAGAGCTTC; DGAT (F), TTCCATGAGTACCTGGTGAGC and DGAT (R), GATGATGAGTGACAGCCACACA; and 16S (F), CAGAAACAAAATTATTCGCCAGAGT and $16 \mathrm{~S}$ (R), GGGTATAAAGCACCGCCAAGT.

The RT-PCR analysis was performed with StepOne software v2.1 (Applied Biosystems Inc.). The proportional change in mRNA was shown as fold change [i.e., the change between mRNA expression with treatment and without (control)]. Efficacy of amplification was calculated from the standard curve of each gene.

\section{Analysis of Plasma Insulin Concentration}

Plasma insulin was determined by RIA using the DSL-1600 caprine insulin RIA kit (Diagnostic Systems
Laboratories Inc., Webster, TX) according to the manufacturer's instructions. The intraassay coefficient of variation was $5.1 \%$ and the interassay coefficient of variation averaged $7.2 \%$.

\section{Statistical Analysis}

All statistical analysis procedures for milk and plasma lipid composition and concentration were performed using JMP software version 7 (SAS Institute Inc., Cary, NC). Treatment, goat number, and day were used as the model effects. The results for gene expression were tested by Student's $t$-test. All dependent variables were checked for normality by goodness-of-fit application of the distribution analysis and unequal variances of JMP. No variables were transformed, but outliers were removed from the analysis. All reported data are least squares means \pm standard error. Significance was set at $\alpha<0.05$.

\section{RESULTS}

\section{Insulin Clamp}

Plasma insulin was elevated 3.5 times $(P<0.002)$ and plasma glucose concentration remained stable throughout the insulin clamp period (Table 2). Glucose infusion during the loading period averaged $8.44 \pm 2.45$ $\mathrm{g} / \mathrm{h}$, depending on the needs of the goat.

\section{DMI and Milk Production and Composition}

During the insulin clamp period, a dramatic decrease $(28 \%, P<0.0001)$ in feed intake $(\mathrm{kg} / \mathrm{d})$ was observed (Table 2), amounting to a $26 \%$ reduction when expressed as grams per kilogram of $\mathrm{BW}^{0.75}(P<0.0001)$. Similarly, milk yield decreased significantly by $21 \%(P$

Table 2. Feed intake, milk yield and composition, and plasma glucose and insulin concentrations (LSM \pm SE) of goats during control and 4-d hyperinsulinemic-euglycemic clamp treatment

\begin{tabular}{lccc}
\hline Item & Control $^{1}$ & Treatment $^{2}$ & $P$-value \\
\hline Feed intake $(\mathrm{kg} / \mathrm{d})$ & $2.19 \pm 0.1$ & $1.57 \pm 0.08$ & 0.0001 \\
Feed intake $\left(\mathrm{g} / \mathrm{kg}\right.$ of $\left.\mathrm{BW}^{0.75}\right)$ & $117.4 \pm 3.7$ & $84.4 \pm 4.06$ & 0.0001 \\
Milk yield $(\mathrm{kg} / \mathrm{d})$ & $2.21 \pm 0.08$ & $1.75 \pm 0.11$ & 0.003 \\
Milk composition $(\%)$ & & & \\
Fat & $2.82 \pm 0.1$ & $3.09 \pm 0.14$ & 0.12 \\
Protein & $3.27 \pm 0.05$ & $3.71 \pm 0.07$ & 0.0001 \\
Lactose & $4.22 \pm 0.02$ & $4.03 \pm 0.03$ & 0.0001 \\
Milk component yield $(\mathrm{g} / \mathrm{d})$ & & & \\
Fat & $60.8 \pm 2.48$ & $51.5 \pm 3.51$ & 0.039 \\
Protein & $72.7 \pm 2.90$ & $63.3 \pm 4.09$ & 0.07 \\
Lactose & $94.1 \pm 3.74$ & $72.0 \pm 5.29$ & 0.002 \\
Plasma glucose $(\mathrm{mg} / \mathrm{dL})$ & $63.2 \pm 1.03$ & $62.6 \pm 1.11$ & 0.69 \\
Plasma insulin $(\mu \mathrm{IU} / \mathrm{mL})$ & $14.56 \pm 5.94$ & $51.36 \pm 9.05$ & 0.002 \\
\hline
\end{tabular}

${ }^{1}$ Control involved continuous i.v. infusions of saline $(240 \mathrm{~g} / \mathrm{d}, \mathrm{pH} 7.4)$.

${ }^{2}$ Treatment involved i.v. infusion of insulin $(10 \mathrm{~mL} / \mathrm{h})$ through a sterile filter $(0.45 \mu \mathrm{m})$ to deliver $120 \mu \mathrm{g}$ of insulin/h. 
Table 3. Plasma FA composition (mole \%; LSM \pm SE) of goats during control and 4 d hyperinsulinemiceuglycemic clamp treatment

\begin{tabular}{lccc}
\hline Item & Control $^{1}$ & Treatment $^{2}$ & $P$-value \\
\hline PUFA & $38.1 \pm 0.3$ & $36.4 \pm 0.4$ & 0.21 \\
MUFA & $20.1 \pm 0.6$ & $24.03 \pm 0.9$ & 0.18 \\
SFA, total & $41.6 \pm 0.9$ & $39.4 \pm 0.14$ & 0.42 \\
C8:0-C15:1; total & $2.05 \pm 0.15$ & $1.62 \pm 0.22$ & 0.36 \\
C8:0-C15:0; saturated & $1.52 \pm 0.15$ & $1.1 \pm 0.2$ & 0.43 \\
C17:0-C24:0; saturated & $22.5 \pm 0.6$ & $20.5 \pm 0.8$ & 0.31 \\
C17:0-C24:0; total & $78.8 \pm 0.6$ & $78.6 \pm 0.2$ & 0.49 \\
n-3 & $0.93 \pm 0.03$ & $0.9 \pm 0.05$ & 0.79 \\
n-6 & $36.8 \pm 0.24$ & $35.1 \pm 0.34$ & 0.15 \\
\hline
\end{tabular}

${ }^{1}$ Control involved continuous i.v. infusions of saline $(240 \mathrm{~g} / \mathrm{d}, \mathrm{pH} 7.4)$.

${ }^{2}$ Treatment involved i.v. infusion of insulin $(10 \mathrm{~mL} / \mathrm{h})$ through a sterile filter $(0.45 \mu \mathrm{m})$ to deliver $120 \mu \mathrm{g}$ of insulin/h.

$<0.003$ ) during the insulin clamp period (Table 2). Milk fat and lactose yields were decreased by $15(P$ $<0.039)$ and $24 \%(P<0.02)$, respectively, whereas milk protein yields tended toward a decrease $(P<$ $0.07)$. Milk fat percentage tended toward an increase $(P<0.12)$, whereas protein percentage increased significantly $(P<0.0001)$. However, lactose percentage significantly decreased during the insulin clamp period $(P<0.0001)$.

\section{Plasma FA Composition}

No significant differences were observed in mole percentage of the major classes of FA between the control and treatment plasma FA (Table 3). However, all classes showed a numerical decrease $(P>0.1)$ in mole percentage during the insulin clamp period, apart from the MUFA, which were similar in both treatment and controls. The insulin clamp also did not affect the plasma FA concentrations (mg/mL; Table 4). However, total FA concentration $(\mathrm{mg} / \mathrm{mL})$ in the plasma showed a tendency toward a decrease during the insulin clamp period $(P<0.08)$. Moreover, concentrations of plasma triglycerides, cholesterol, and phospholipids were similar in both treatment and controls (Table 4).

\section{Milk FA Yield (g/d and Mole \%)}

Detailed results of the effect of the insulin clamp on milk FA yields (g/d) are shown in Table 5. Capric acid (C10:0) and lauric acid (C12:0) yield (g/d) did not change, whereas myristic acid (C14:0) and pentadecanoic acid $(\mathrm{C} 15: 0)$ decreased by $16(P<0.039)$ and $33 \%$ $(P<0.0001)$, respectively, during the insulin clamp period. The yield of palmitic acid (C16:0) decreased by $16 \%(P<0.039)$ but palmitoleic acid $(\mathrm{C} 16: 1 \mathrm{n}-7)$ did not show any significant change. Most of the long-chain FA secreted in milk decreased (Table 5). For example, stearic acid (C18:0), oleic acid (C18:1n-9), linoleic acid (C18:2n-6), $\alpha$-linolenic acid (C18:3n-3), $\gamma$-linolenic (C18:3n-6) acid, eicosapentaenoic acid (EPA, C20:5n-3), and docosahexaenoic acid (DHA, C22:6n-3) decreased

Table 4. Plasma FA composition $(\mathrm{mg} / \mathrm{mL} ; \mathrm{LSM} \pm \mathrm{SE})$ of goats during control and 4-d hyperinsulinemiceuglycemic clamp treatment

\begin{tabular}{lccc}
\hline Item & Control $^{1}$ & Treatment $^{2}$ & $P$-value \\
\hline PUFA & $1.445 \pm 0.017$ & $1.35 \pm 0.02$ & 0.18 \\
MUFA & $0.75 \pm 0.01$ & $0.89 \pm 0.02$ & 0.14 \\
SFA, total & $1.5 \pm 0.03$ & $1.4 \pm 0.04$ & 0.28 \\
C8:0-C15:1 & $0.05 \pm 0.002$ & $0.04 \pm 0.004$ & 0.22 \\
C8:0-C15:0; saturated & $0.041 \pm 0.002$ & $0.03 \pm 0.003$ & 0.27 \\
C17:0-C24:0; saturated & $0.86 \pm 0.01$ & $0.77 \pm 0.02$ & 0.2 \\
C17:0-C24:0; total & $3.31 \pm 0.01$ & $2.9 \pm 0.01$ & 0.18 \\
n-3 & $0.03 \pm 0.001$ & $0.03 \pm 0.002$ & 0.72 \\
n-6 & $1.4 \pm 0.01$ & $1.3 \pm 0.01$ & 0.08 \\
Total FA & $3.73 \pm 0.005$ & $3.66 \pm 0.007$ & 0.34 \\
Triglycerides & $2.37 \pm 0.157$ & $2.18 \pm 0.047$ & 0.80 \\
Cholesterol & $0.20 \pm 0.009$ & $0.16 \pm 0.042$ & 0.18 \\
Phospholipids & $0.70 \pm 0.085$ & $0.52 \pm 0.058$ & \\
\hline
\end{tabular}

${ }^{1}$ Control involved continuous i.v. infusions of saline $(240 \mathrm{~g} / \mathrm{d}, \mathrm{pH} 7.4)$.

${ }^{2}$ Treatment involved i.v. infusion of insulin $(10 \mathrm{~mL} / \mathrm{h})$ through a sterile filter $(0.45 \mu \mathrm{m})$ to deliver $120 \mu \mathrm{g}$ of insulin/h. 
Table 5. Milk FA yield (g/d; LSM \pm SE) of goats during control and 4-d hyperinsulinemic-euglycemic clamp treatment

\begin{tabular}{|c|c|c|c|}
\hline $\mathrm{FA}^{1}$ & Control $^{2}$ & Treatment $^{3}$ & $P$-value \\
\hline C8:0 & $0.52 \pm 0.039$ & $0.65 \pm 0.056$ & 0.07 \\
\hline C10:0 & $3.42 \pm 0.194$ & $3.72 \pm 0.274$ & 0.37 \\
\hline C10:1 & $0.15 \pm 0.008$ & $0.13 \pm 0.011$ & 0.2 \\
\hline C12:0 & $2.12 \pm 0.143$ & $2.34 \pm 0.202$ & 0.37 \\
\hline C12:0 BC(a) & $0.07 \pm 0.003$ & $0.06 \pm 0.005$ & 0.27 \\
\hline $\mathrm{C} 12: 0 \mathrm{BC}(\mathrm{b})$ & $0.04 \pm 0.002$ & $0.03 \pm 0.0033$ & 0.6 \\
\hline C13:0 & $0.03 \pm 0.001$ & $0.02 \pm 0.002$ & 0.03 \\
\hline C14:0 & $5.63 \pm 0.249$ & $4.71 \pm 0.353$ & 0.039 \\
\hline C14:1 & $0.033 \pm 0.002$ & $0.02 \pm 0.003$ & 0.006 \\
\hline C14:1 BC(a) & $0.16 \pm 0.0121$ & $0.10 \pm 0.017$ & 0.004 \\
\hline C14:1 BC(b) & $0.19 \pm 0.011$ & $0.12 \pm 0.015$ & 0.0005 \\
\hline C15:0 & $0.42 \pm 0.017$ & $0.28 \pm 0.025$ & 0.0001 \\
\hline C15:1 & $0.11 \pm 0.006$ & $0.06 \pm 0.009$ & 0.0001 \\
\hline C16:0 & $13.19 \pm 0.543$ & $11.08 \pm 0.768$ & 0.03 \\
\hline C16:1(a) & $0.16 \pm 0.007$ & $0.16 \pm 0.011$ & 0.7 \\
\hline C16:1(b) & $0.26 \pm 0.012$ & $0.22 \pm 0.018$ & 0.07 \\
\hline C16:1n-7 & $0.32 \pm 0.015$ & $0.29 \pm 0.022$ & 0.25 \\
\hline C16:1 BC(a) & $0.32 \pm 0.025$ & $0.21 \pm 0.036$ & 0.02 \\
\hline C16:1 BC(b) & $0.21 \pm 0.012$ & $0.14 \pm 0.017$ & 0.001 \\
\hline C17:0 & $0.24 \pm 0.0149$ & $0.13 \pm 0.021$ & 0.0002 \\
\hline C17:1 & $0.1 \pm 0.006$ & $0.09 \pm 0.008$ & 0.5 \\
\hline C18:0 & $5.61 \pm 0.247$ & $4.43 \pm 0.349$ & 0.01 \\
\hline trans $\mathrm{C} 18: 1 \mathrm{n}-9$ & $1.29 \pm 0.066$ & $1.00 \pm 0.094$ & 0.01 \\
\hline cis $\mathrm{C} 18: 1 \mathrm{n}-9$ & $12.02 \pm 0.525$ & $9.83 \pm 0.7427$ & 0.02 \\
\hline C18:1n-7 & $0.52 \pm 0.030$ & $0.35 \pm 0.043$ & 0.04 \\
\hline trans-9,trans-12 C18:2n-6 & $0.37 \pm 0.028$ & $0.24 \pm 0.040$ & 0.017 \\
\hline cis-9,cis-12 C18:2n-6 & $1.95 \pm 0.099$ & $1.56 \pm 0.141$ & 0.031 \\
\hline C18:3n-6 & $0.06 \pm 0.008$ & $0.02 \pm 0.012$ & 0.022 \\
\hline C18:3n-3 & $0.06 \pm 0.003$ & $0.05 \pm 0.005$ & 0.02 \\
\hline cis-9,trans-11 C18:2n-6 & $0.42 \pm 0.022$ & $0.35 \pm 0.031$ & 0.09 \\
\hline trans-10,cis-12 C18:2 & $0.01 \pm 0.001$ & $0.01 \pm 0.002$ & 0.42 \\
\hline $\mathrm{C} 20: 0$ & $0.08 \pm 0.004$ & $0.06 \pm 0.006$ & 0.018 \\
\hline C20:1n-9 & $0.05 \pm 0.003$ & $0.03 \pm 0.004$ & 0.011 \\
\hline trans-10,cis-12 C18:2n-6 & $0.01 \pm 0.001$ & $0.007 \pm 0.001$ & 0.017 \\
\hline trans-9,trans-11 C18:2 & $0.03 \pm 0.002$ & $0.02 \pm 0.003$ & 0.03 \\
\hline cis-11,cis-13 C20:2 & $0.01 \pm 0.001$ & $0.02 \pm 0.001$ & 0.2 \\
\hline $\mathrm{C} 20: 3 \mathrm{n}-3$ & $0.01 \pm 0.0004$ & $0.008 \pm 0.0006$ & 0.006 \\
\hline C20:4n-6 & $0.09 \pm 0.005$ & $0.09 \pm 0.0079$ & 0.6 \\
\hline $\mathrm{C} 22: 0$ & $0.02 \pm 0.001$ & $0.01 \pm 0.001$ & 0.01 \\
\hline Total & $50.49 \pm 2.067$ & $42.81 \pm 2.923$ & 0.04 \\
\hline
\end{tabular}

${ }^{1} \mathrm{BC}=$ branched-chained $\mathrm{FA}$; (a) and (b) represent different isomers of the respective FA that could not be defined by the GC-MS calibration and the external standards.

${ }^{2}$ Control involved continuous i.v. infusions of saline $(240 \mathrm{~g} / \mathrm{d}, \mathrm{pH} 7.4)$.

${ }^{3}$ Treatment involved i.v. infusion of insulin $(10 \mathrm{~mL} / \mathrm{h})$ through a sterile filter $(0.45 \mu \mathrm{m})$ to deliver $120 \mu \mathrm{g}$ of insulin/h.

by $21,18,20,16,66,37$, and $20 \%$, respectively $(P<$ 0.003 to $P<0.03)$, whereas arachidonic acid was similar for treatments and controls $(P<0.6)$. The overall yields of total FA decreased by $15.2 \%(P<0.04)$ during the clamp period.

The yields of short- and medium-chain FA (C8:0 to C15:1) classes did not differ between the controls and treatments $(P>0.1$; Figure 1$)$, whereas long-chain FA (C17:0 to C24:0, both saturated and total) decreased by 22 and $20 \%$, respectively, during the clamp period $(P<$ 0.06 and $P<0.01$, respectively). Similarly, the yields of n-3, n- 6 , and MUFA were significantly decreased by 22,21 , and $20 \%$, respectively, during the clamp treatment $(P<0.01, P<0.03$, and $P<0.02$, respectively $)$, whereas PUFA were similar between treatments and controls $(P<0.1)$. Total SFA showed a tendency toward a decrease $(12 \%, P<0.1)$.

Changes in the milk FA profile are illustrated in Figure 2. In general, saturated short- and medium-chain FA classes (C8:0 to $\mathrm{C} 15: 0$ saturated $\mathrm{FA}$ and $\mathrm{C} 8: 0$ to C15:1 total FA; mole \%) increased by 14 and $13 \%$, respectively $(P<0.02$ and $P<0.01$, respectively) during the clamp period. On the other hand, MUFA, saturated long-chain FA (C17:0 to C24:0; saturated), total longchain FA (C17:0 to C24:0; total), and branched-chained FA (mole \%) decreased by $6,10,7$, and $18 \%$, respectively, with the insulin clamp $(P<0.03, P<0.008, P$ $<0.02$, and $P<0.003$, respectively). The mole percent- 


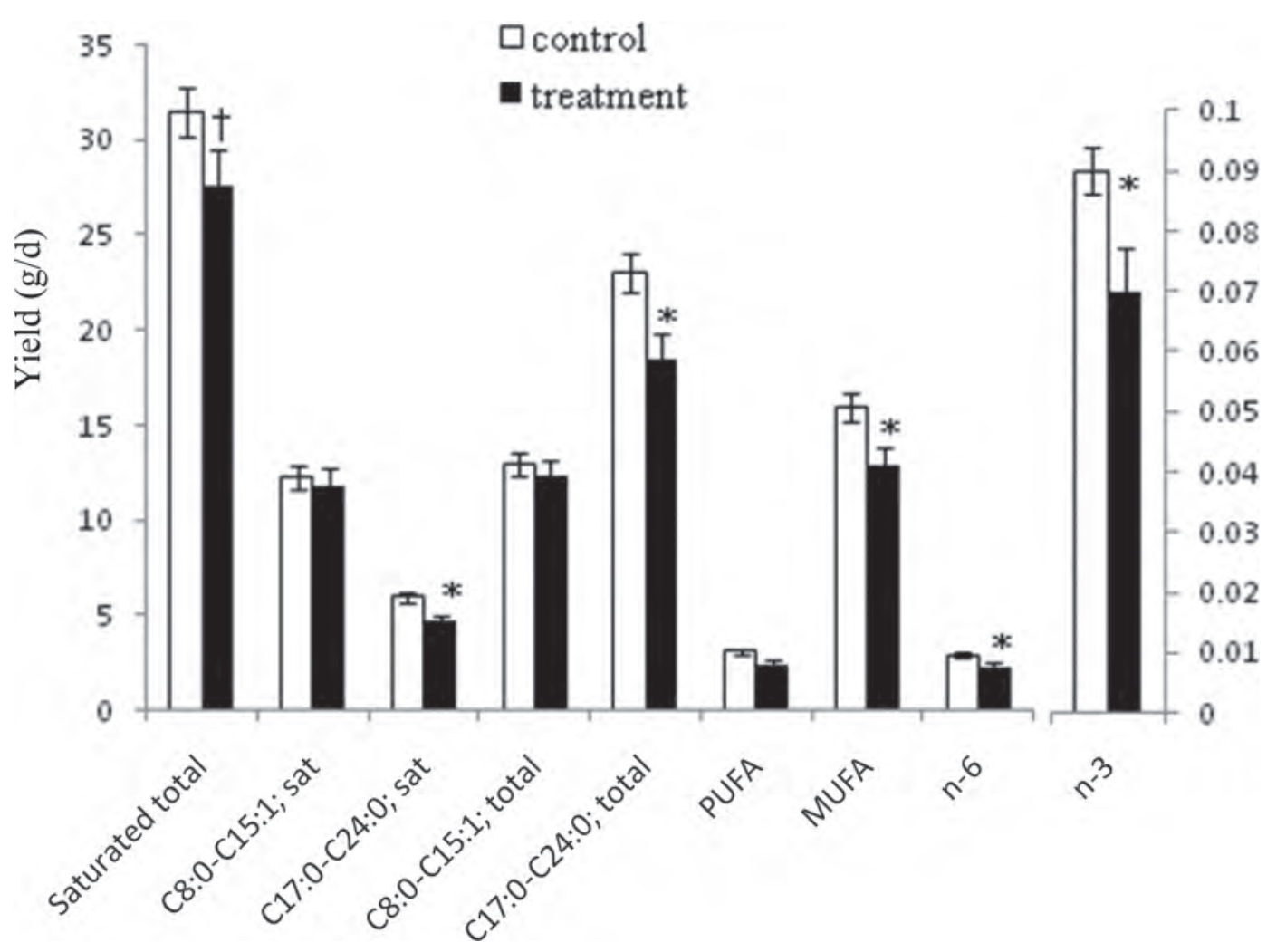

Figure 1. Yield (g/d) of the major FA classes during $4 \mathrm{~d}$ of hyperinsulinemic clamp (treatment) compared with saline infusion (control). Fatty acids were grouped according to their chemical characteristics [saturated (sat), PUFA, MUFA, n-3, and n-6] and their perceived origin: C8:0 to C15:1 are derived from de novo synthesis in the mammary glands; C17:0 to C24:0 are derived from uptake of preformed FA from the diet or adipose lipolysis. The right and left y-axes illustrate FA yield (g/d). Values are means $\pm \mathrm{SE} . \dagger P<0.1 ;{ }^{*} P<0.05$.

age of n-6 and PUFA were similar in both treatment and controls, whereas n-3 FA mole percentage showed a tendency toward reduction $(18 \%, P<0.08)$.

As for the markers of elongation and desaturation, only elongation of palmitoleic acid (C16:1n-7) to vaccenic acid (C18:1n-7) showed a reduction (of 20\%) during the insulin clamp period $(P<0.0005$; Figure 3), whereas the values of all other markers did not differ between control and treatment.

\section{Milk Polar and Neutral Lipid Yields and Weight Percent}

The effect of the treatment on concentrations of the major analyzed polar and neutral lipids in milk is shown in Figure 4. The concentrations of triglycerides $(\mu \mathrm{g} / \mathrm{mL})$ showed a tendency toward a decrease $(10 \%$, $P<0.07$ ), whereas the concentration of phospholipids $(\mu \mathrm{g} / \mathrm{mL})$ increased significantly by $9 \%(P<0.007)$. As for individual phospholipids, only PS showed a significant increase of $29 \%(P<0.04)$. In a determination of weight percent of polar lipids, both $\mathrm{PE}$ and $\mathrm{PC}$ decreased by 13 and $9 \%$, respectively $(P<0.02$ and $P$
$<0.03$, respectively) during the treatment period (Figure 5). Consequently, PS showed a tendency toward an increase $(23.3 \%, P<0.06)$.

\section{Mammary Gland Gene Expression}

Abundance of ACC, FAS, SCD, and DGAT mRNA showed a numerical, albeit nonsignificant, increase during insulin clamp $(P>0.1$; Figure 6$)$. However, the abundance of LPL mRNA showed a tendency toward an increase $(P<0.08)$ with the treatment.

\section{DISCUSSION}

In the present study, hyperinsulinemic clamp treatment was performed in dairy goats that were 150 DIM. Throughout the experimental period, plasma insulin was successfully increased 3.5 fold, with no change in plasma glucose levels. The results suggest that under high insulin concentrations, the lipid composition of the mammary gland epithelial cell membrane is altered, as reflected by changes in the major lipid constituents of the milk fat globule membrane. These compositional 


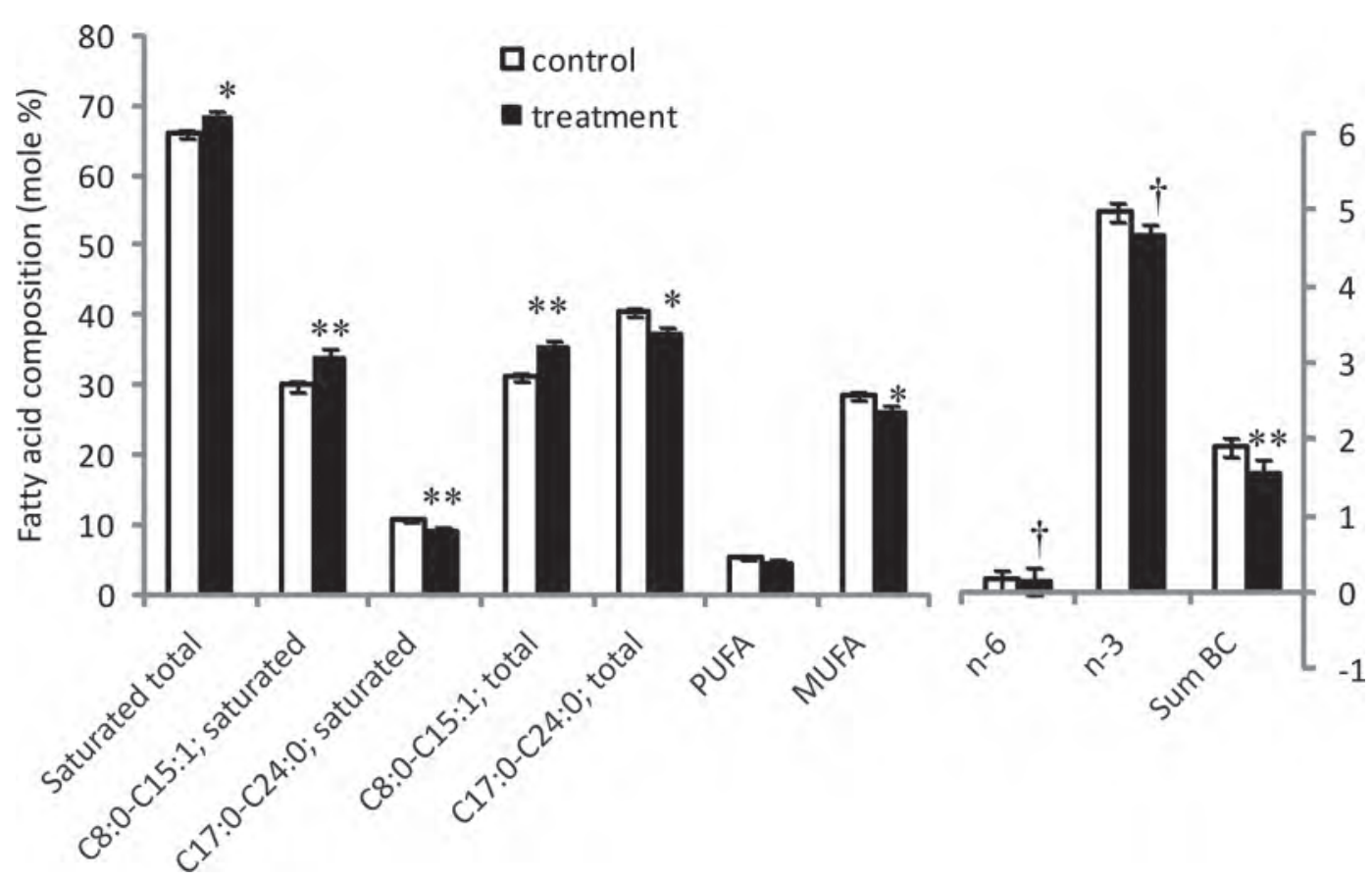

Figure 2. Milk fatty acid composition (mole \%) of the major FA classes during $4 \mathrm{~d}$ of hyperinsulinemic clamp (treatment) compared with saline infusion (control). Fatty acids were grouped according to their chemical characteristics (saturated PUFA, MUFA, n-3, and n-6) and their perceived origin: C8:0 to C15:1 are derived from de novo synthesis in the mammary glands; C17:0 to C24:0 are derived from uptake of preformed FA from the diet or adipose lipolysis. The right and left y-axes illustrate FA composition (mole \%). Sum BC = sum of the branched-chain FA. Values are means \pm SE. $\dagger P<0.1 ; * P<0.05 ;{ }^{* *} P<0.01$.

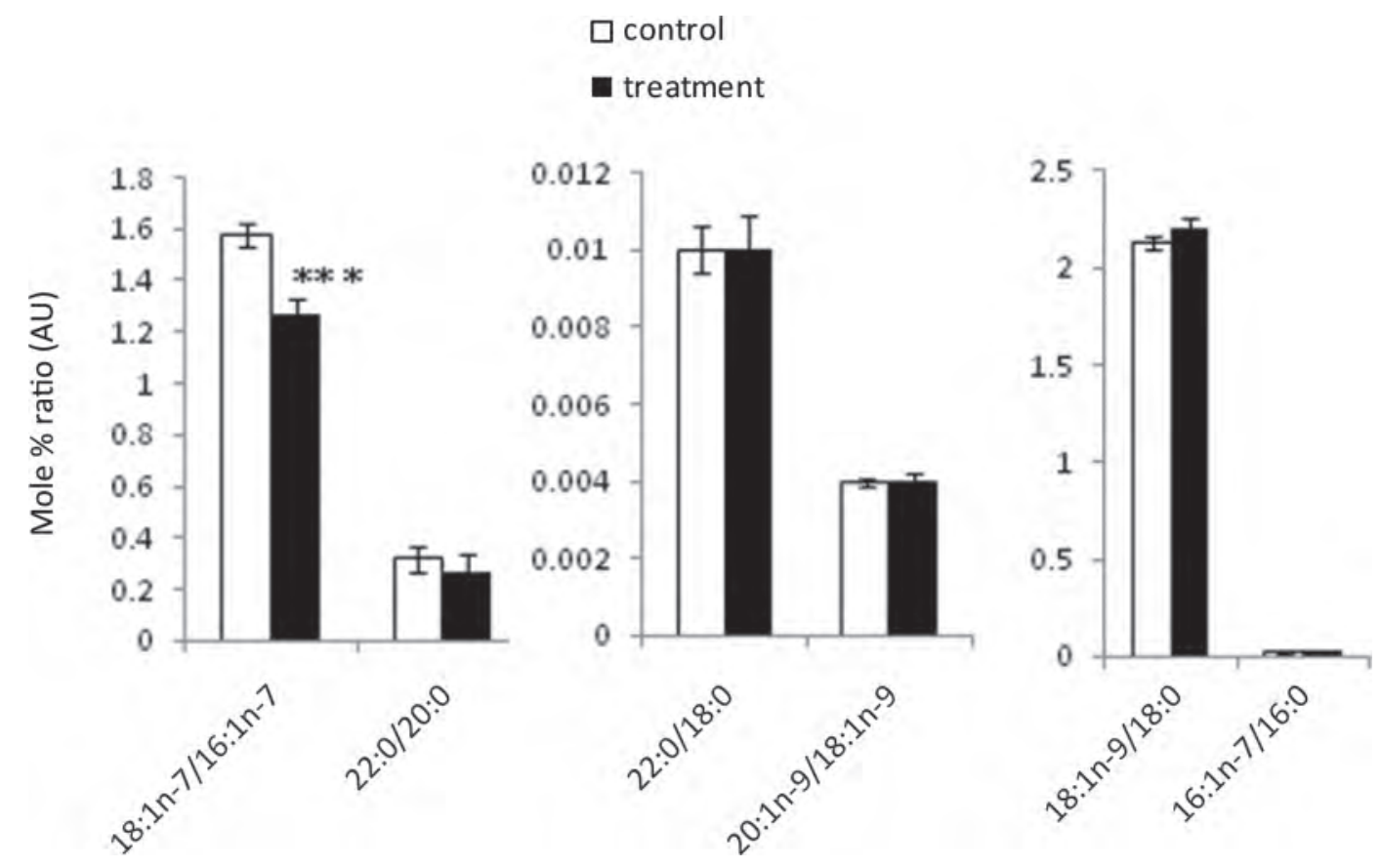

Figure 3. Markers of elongation and desaturation during $4 \mathrm{~d}$ of hyperinsulinemic clamp (treatment) compared with saline infusion (control). The ratio between the product and substrate yields $(\mathrm{g} / \mathrm{d})$ was used to estimate the flux of FA through the elongation or desaturation pathways. Values are means \pm SE. ${ }^{* * *} P<0.001$. 


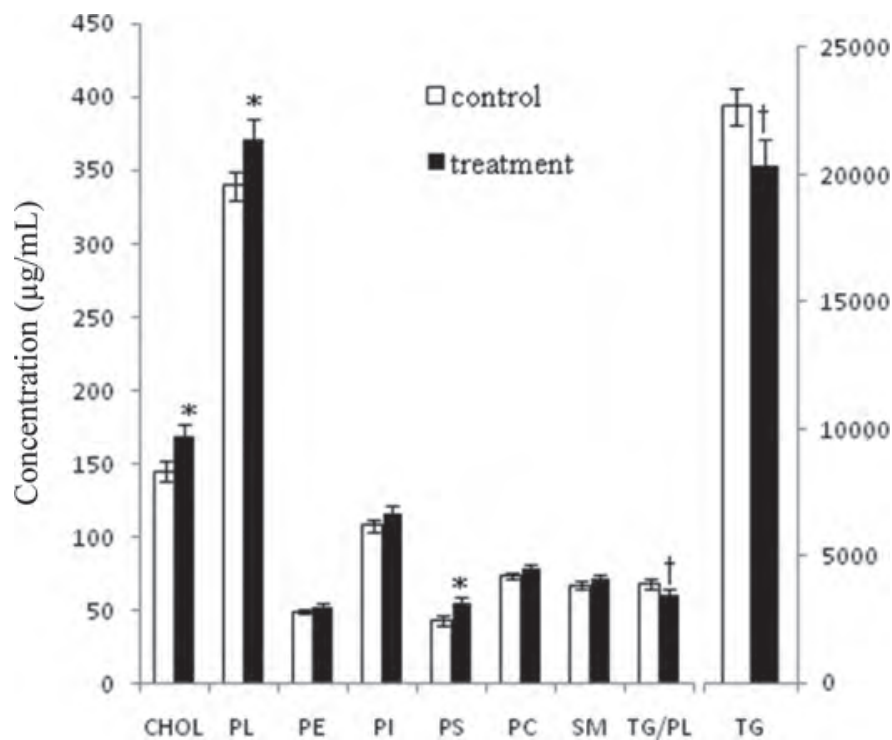

Figure 4. Concentration $(\mu \mathrm{g} / \mathrm{mL})$ of neutral (triglyceride) and polar (phospholipids) lipids in milk during $4 \mathrm{~d}$ of hyperinsulinemic clamp (treatment) compared with saline infusion (control). The triglycerideto-phospholipid ratio was obtained by dividing the total concentration of triglycerides by the total concentration of phospholipids $(\mu \mathrm{g} / \mathrm{mL})$ in the milk sample. $\mathrm{CHOL}=$ cholesterol; $\mathrm{PL}=$ phospholipids; $\mathrm{PE}=$ phosphatidylethanolamine; $\mathrm{PI}=$ phosphatidylinositol; PS = phosphatidylserine; $\mathrm{PC}=$ phosphatidylcholine; $\mathrm{SM}=$ sphingomyelin; $\mathrm{TG}=$ triglycerides. The right and left y-axes illustrate milk lipid concentration $(\mu \mathrm{g} / \mathrm{mL})$. Values are means \pm SE. $\dagger P<0.1 ;{ }^{*} P<0.05$.

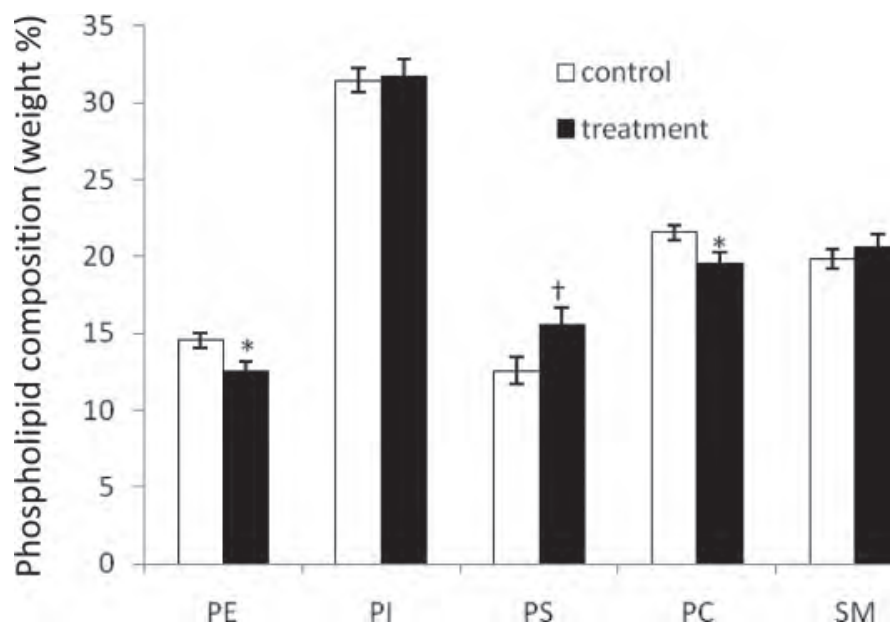

Figure 5. Weight percent of phospholipids during $4 \mathrm{~d}$ of hyperinsulinemic clamp (treatment) compared with saline infusion (control). Weight percent was calculated by dividing the weight $(\mu \mathrm{g})$ of each phospholipid by the total weight of all phospholipids present in $1 \mathrm{~mL}$ of sample. $\mathrm{PE}=$ phosphatidylethanolamine; $\mathrm{PI}=$ phosphatidylinositol; $\mathrm{PS}=$ phosphatidylserine; $\mathrm{PC}=$ phosphatidylcholine; $\mathrm{SM}=$ sphingomyelin. Values are means \pm SE. $\dagger P<0.1 ;{ }^{*} P<0.05$.

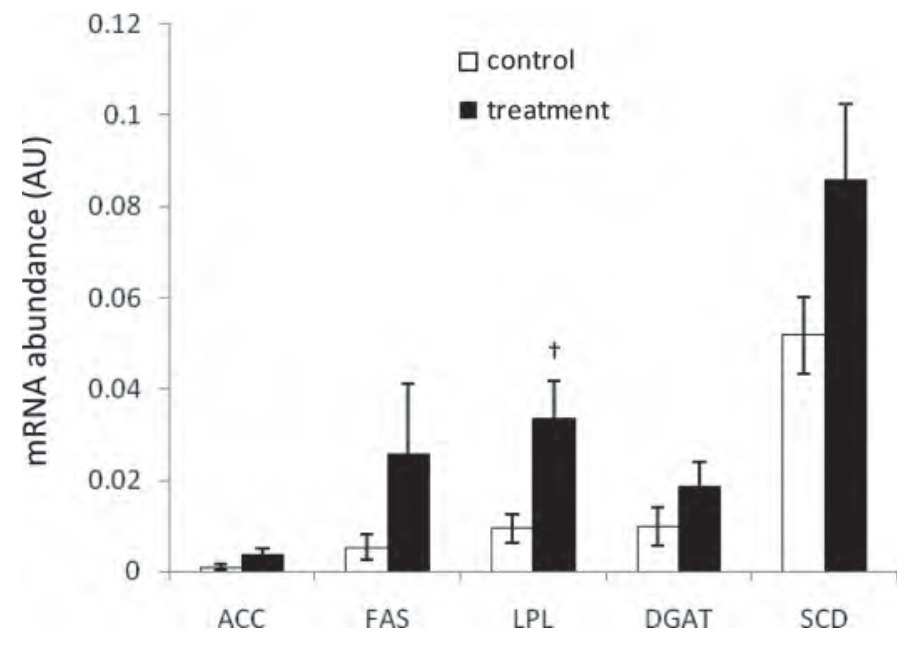

Figure 6. Gene expression levels of acetyl-CoA carboxylase (ACC), FA synthase (FAS), lipoprotein lipase (LPL), diacylglycerol acyltransferase (DGAT), and stearoyl-CoA desaturase (SCD) in mammary gland tissues during $4 \mathrm{~d}$ of hyperinsulinemic clamp (treatment) compared with saline infusion (control). The proportional change detected in mRNA is shown as fold change. Values are means \pm SE. $\dagger P<0.1$.

changes were associated with lower milk fat yield and a tendency toward higher milk fat concentration.

A hyperinsulinemic clamp has been previously used in goats to study the effects of insulin on milk protein synthesis and composition (Bequette et al., 2002). Similar studies focusing on milk fat concentration, yield, and FA composition have been conducted in dairy cows (Griinari et al., 1997; Corl et al., 2006). To the best of our knowledge, this is the first study to determine the effect of insulin clamp on milk lipid components in dairy goats, and to use this model to determine insulin's effect on milk lipid species and the composition of the milk fat globule membrane.

In the present study, milk yield decreased by $26 \%$ in the treatment period compared with the control. This could be attributed to reduced feed intake due to the hyperinsulinemic clamp, as has been described in previous studies in dairy cows (McGuire at al., 1995; Griinari et al., 1997; Molento et al., 2002). The decreased feed intake could also result in altered rumen fermentation characteristics and, consequently, will reduce milk fat yield. Decreased milk fat yield with hyperinsulinemic clamp treatment has been reported previously (Mackle et al., 1999; Bequette et al., 2001; Molento et al., 2002). However, Griinari et al. (1997) observed a nonsignificant numerical decrease in Holstein cows 180 d postpartum, whereas McGuire et al. (1995) reported no change in milk fat yield in Holstein cows in early lactation stages when subjected to hyperinsulinemic clamp. These inconsistencies imply that lactation stage interacts with the hyperinsulinemic treatment in terms of its effect on 
milk fat yields. Elevated circulating insulin is presumed to increase the uptake of lipogenic precursors (acetate and $\mathrm{BHBA}$ ) and decrease the process of $\mathrm{FA}$ release in adipose tissues (Bauman and Griinari, 2001; Li et al., 2007). A reduction in lipogenic precursors limits the mammary gland's ability to synthesize short- and medium-chain FA, which are considered locally synthesized by the gland (Kinsella and McCarthy, 1968). However, in the present study, we found that high insulin concentration only reduced myristic (C14:0) and C15:0 yields, whereas the yields of all other identified medium-chain FA were not affected by the treatment. Nonetheless, the yields of almost all long-chain $(>16 \mathrm{C})$ FA, which are considered to be absorbed from the circulation (i.e., preformed FA; Kinsella and McCarthy, 1968), were reduced by the elevated circulating insulin concentrations. This implies that the reduction in milk fat yield during the treatment period is due to reduced long-chain FA output by the gland, in agreement with the studies conducted in dairy cows (McGuire et al., 1995; Molento et al., 2002; Corl et al., 2006). The reduction in long-chain FA yield was most likely due to the reduced feed intake and not to reduced adipose lipolysis, because no significant changes in plasma NEFA concentration were found during the treatment period compared with controls.

Compared with the control, treatment increased the proportion of medium-chain FA in milk, with the concomitant reduced concentration of long-chain FA, which is in agreement with previous studies (Griinari et al., 1997; Molento et al., 2002; Corl et al., 2006). The elevated proportion of medium-chain FA could be attributed to the reduction in long-chain FA proportions in milk or to elevated production of medium-chain FA.

Medium-chain FA, usually relating to a chain length of 8 to $14 \mathrm{C}$, are considered to be the product of de novo synthesis in the gland (Kinsella, 1970) by the lipogenic enzymes ACC and FAS. The genes encoding these enzymes are under the regulation of a sterol regulatory element (SRE) in their promoter region, which is activated by SRE-binding proteins (You et al., 2002). The translocation of SRE-binding proteins from endoplasmic reticulum to the nucleus to induce gene expression of lipogenic enzymes is insulin pathway dependent (Dong and Tang, 2010). Hence, the hyperinsulinemic clamp was expected to increase the expression of these genes. However, in the present study, insulin did not induce any significant changes in the expression levels of the major lipogenic genes under SRE regulation, such as SCD, LPL, ACC, and FAS. This could be due to high individual variability among the animals in the study. Although SCD gene expression was significantly changed relative to controls, both yield and concentrations of the primary products of its activity (MUFA) were reduced during the treatment period. The decrease in MUFA in the present study was mostly attributed to oleic acid (C18:1n-9), which is considered to be derived from the circulation. This reduction can, therefore, be attributed to reduced feed intake and possible reduction in adipose lipolysis.

The above results suggest reduced availability of preformed FA, derived from the circulation, for the mammary gland. Indeed, the yields of essential n-3 and n-6 PUFA, which derive only from the circulation, were significantly reduced by the elevated insulin concentration. Triglyceride yields tended to decrease, whereas yields of phospholipid and cholesterol, the major lipid components of the milk fat globule membrane, increased in response to increased insulin concentrations. This might indicate that, under reduced availability of longchain FA, and especially PUFA, the mammary gland channels more of these FA to the phospholipid fraction, which is necessarily polyunsaturated, rather than to the triglyceride fraction, which is mostly comprises SFA and MUFA (Jensen, 2002). An additional explanation for the reduced triglyceride yield might be the reduced availability of glycerol to the mammary gland, which is usually derived from glucose and is needed as a backbone for triglyceride synthesis (Coleman and Lee, 2004). Nonetheless, it should be noted that in the present study, glucose concentration in the treatment period did not differ from that of the control.

\section{CONCLUSIONS}

The observed changes in phospholipid-to-triglyceride ratio have been shown to be associated with milk fat concentration and milk fat globule mean diameter (Lopez et al., 2008, 2011; Mesilati-Stahy et al., 2011). Interestingly, both dietary manipulation (Lopez et al., 2008) and hyperinsulinemic clamp in conjugation with feed intake (present study), which induced a reduction in milk fat yields, induced compositional changes in the membrane lipids. However, although in the present study, treatment induced changes in $\mathrm{PE}$ and $\mathrm{PC}$ concentrations, the diet-induced compositional changes were associated with a $30 \%$ elevation in sphingomyelin concentrations. These results suggest a role for lipid membrane composition in determining fat composition and concentration in milk, and that the membrane composition might be subject to the model used to change fat content in milk.

\section{REFERENCES}

Ahnadi, C. E., N. Beswick, L. Delbecchi, J. J. Kennelly, and P. Lacasse. 2002. Addition of fish oil to diets for dairy cows. II. Effects on milk fat and gene expression of mammary lipogenic enzymes. J. Dairy Res. 69:521-531. 
Argov-Argaman, N., J. T. Smilowitz, D. A. Bricarello, M. Barboza, L. Lerno, J. W. Froehlich, H. Lee, A. M. Zivkovic, D. G. Lemay, S. Freeman, C. B. Lebrilla, A. N. Parikh, and J. B. German. 2010. Lactosomes: Structural and compositional classification of unique nanometer-sized protein lipid particles of human milk. J. Agric. Food Chem. 58:11234-11242.

Bauman, D. E., and J. M. Griinari. 2001. Regulation and nutritional manipulation of milk fat: Low-fat milk syndrome. Livest. Prod. Sci. 70:15-29.

Bequette, B. J., C. E. Kyle, L. A. Crompton, S. E. Anderson, and M. D. Hanigan. 2002. Protein metabolism in lactating goats subjected to the insulin clamp. J. Dairy Sci. 85:1546-1555.

Bequette, B. J., C. E. Kyle, L. A. Crompton, V. Buchan, and H. D. Hanigan. 2001. Insulin regulates milk production and mammary gland and hind-leg amino acid fluxes and blood flow in lactating goats. J. Dairy Sci. 84:241-255.

Bernard, L., C. Leroux, M. Bonnet, J. Rouel, P. Martin, and Y. Chilliard. 2005. Expression and nutritional regulation of lipogenic genes in mammary gland and adipose tissues of lactating goats. J. Dairy Res. 72:250-255.

Bernard, L., C. Leroux, and Y. Chilliard. 2008. Expression and nutritional regulation of lipogenic genes in the ruminant lactating mammary gland. Adv. Exp. Med. Biol. 606:67-108.

Bitman, J., and D. L. Wood. 1990. Changes in milk fat phospholipids during lactation. J. Dairy Sci. 73:1208-1216.

Brockman, R. P., and B. Laarveld. 1986. Hormonal regulation of metabolism in ruminants; a review. Livest. Prod. Sci. 14:313-334.

Chilliard, Y., A. Ferlay, J. Rouel, and G. Lamberet. 2003. A review of nutritional and physiological factors affecting goat milk lipid synthesis and lipolysis. J. Dairy Sci. 86:1751-1770.

Chomczynski, P., and N. Sacchi. 1987. Single step method of RNA isolation by acid guanidinium thiocyanate-phenol-chloroform extraction. Anal. Biochem. 162:156-159.

Coleman, R. A., and D. P. Lee. 2004. Enzymes of triacylglycerol synthesis and their regulation. Prog. Lipid Res. 43:134-176.

Corl, B. A., S. T. Butler, W. R. Butler, and D. E. Bauman. 2006. Regulation of milk fat yield and fatty acid composition by insulin. J. Dairy Sci. 89:4172-4175.

de Vries, M. J., and R. F. Veerkamp. 2000. Energy balance of dairy cattle in relation to milk production variables and fertility. J. Dairy Sci. 83:62-69.

Dong, X.-Y., and S.-Q. Tang. 2010. Insulin-induced gene: A new regulator in lipid metabolism. Peptides 31:2145-2150.

Folch, J., M. Lees, and G. H. Sloane-Stanley. 1957. A simple method for the isolation and purification of total lipids from animal tissues. J. Biol. Chem. 226:497-509.

Glunde, K., C. Jie, and Z. M. Bhujwalla. 2004. Molecular causes of the aberrant choline phospholipid metabolism in breast cancer. Cancer Res. 64:4270-4276.

Golovastov, V. V., S. N. Zolov, and M. A. Nesmeyanova. 2002. Study of interaction of export initiation domain of Escherichia coli mature alkaline phosphatase with membrane phospholipids during secretion. Biochemistry (Mosc.) 67:978-985.

Griinari, J. M., M. A. McGuire, D. A. Dwyer, D. E. Bauman, and D. L. Palmquist. 1997. Role of insulin in the regulation of milk fat synthesis in dairy cows. J. Dairy Sci. 80:1076-1084.

Jenny, B. F., C. E. Polan, and F. W. Thye. 1974. Effects of high grain feeding and stage of lactation on serum insulin, glucose and milk fat percentage in lactating cows. J. Nutr. 104:379-385.

Jensen, R. G. 2002. The composition of bovine milk lipids: January 1995 to December 2000. J. Dairy Sci. 85:295-350.
Jensen, R. G., and M. P. Thompson. 1995. Handbook of Milk Composition. Academic Press, San Diego, CA.

Kinsella, J. E. 1970. The absorption of fatty acids by functional bovine mammary cells. Lipids 5:892-895.

Kinsella, J. E., and R. D. McCarthy. 1968. Biosynthesis of secretory lipids from $\left[2{ }^{14} \mathrm{C}\right]$ acetate by bovine mammary cells in vitro. Biochim. Biophys. Acta 164:518-529.

Li, B., Z. H. Wang, F. C. Li, and X. Y. Lin. 2007. Milk fat content was changed by ruminal infusion of mixed VFAs solutions with different acetate/propionate ratios in lactating goats. Small Rumin. Res. 72:11-17.

Lopez, C., V. Briard-Bion, O. Ménard, E. Beaucher, F. Rousseau, J. Fauquant, N. Leconte, and B. Robert. 2011. Fat globules selected from whole milk according to their size: Different compositions and structure of the biomembrane, revealing sphingomyelin-rich domains. Food Chem. 125:355-368.

Lopez, C., V. Briard-Bion, O. Ménard, F. Rousseau, P. Pradel, and J. Besle. 2008. Phospholipid, sphingolipid, and fatty acid composition of the milk fat globule membrane are modified by diet. J. Agric. Food Chem. 56:5226-5236.

Mackle, T. R., D. A. Dwyer, K. L. Ingvartsen, P. Y. Chouinard, J. M. Lynch, D. M. Barbano, and D. E. Bauman. 1999. Effects of insulin and amino acids on milk protein concentration and yield from dairy cows. J. Dairy Sci. 82:1512-1524.

Mather, I. H., and T. W. Keenan. 1998. Origin and secretion of milk lipids. J. Mammary Gland Biol. Neoplasia 3:259-273.

McGuire, M. A., J. M. Griinari, D. A. Dwyer, and D. E. Bauman. 1995. Role of insulin in the regulation of mammary synthesis of fat and protein. J. Dairy Sci. 78:816-824.

Mesilati-Stahy, R., K. Mida, and N. Argov-Argaman. 2011. Size-dependent lipid content of bovine milk fat globule and membrane phospholipids. J. Agric. Food Chem. 59:7427-7435.

Mikhaleva, N. I., V. V. Golovastov, S. N. Zolov, M. V. Bogdanov, W. Dowhan, and M. A. Nesmeyanova. 2001. Depletion of phosphatidylethanolamine affects secretion of Escherichia coli alkaline phosphatase and its transcriptional expression. FEBS Lett. 493:85-90.

Molento, C. F. M., E. Block, R. I. Cue, and D. Petitclerc. 2002. Effects of insulin, recombinant bovine somatotropin, and their interaction on insulin-like growth factor-I secretion and milk production in dairy cows. J. Dairy Sci. 85:738-747.

Ollier, S., C. Leroux, A. de la Foye, L. Bernard, J. Rouel, and Y. Chilliard. 2009. Whole intact rapeseeds or sunflower oil in highforage or high-concentrate diets affects milk yield, milk composition, and mammary gene expression profile in goats. J. Dairy Sci. 92:5544-5560.

Storlien, L. H., D. A. Pan, A. D. Kriketos, J. O'Connor, I. D. Caterson, G. J. Cooney, A. B. Jenkins, and L. A. Baur. 1996. Skeletal muscle membrane lipids and insulin resistance. Lipids 31:S261S265.

Sutton, J. D., I. C. Hart, S. V. Morant, E. Schuller, and A. D. Simmonds. 1988. Feeding frequency for lactating cows: Diurnal patterns of hormones and metabolites in peripheral blood in relation to milk-fat concentration. Br. J. Nutr. 60:265-274.

Yandrasitz, J. R., G. Berry, and S. Segal. 1981. High-performance lipid chromatography of phospholipids with UV detection: Optimization of separations on silica. J. Chromatogr. 225:319-328.

You, M., M. Fischer, M. A. Deeg, and D. W. Crabb. 2002. Ethanol induces fatty acid synthesis pathways by activation of sterol regulatory element-binding protein (SREBP). J. Biol. Chem. 277:29342-29347. 